\title{
MATRIZ PARA SELEÇÃO TIPOGRÁFICA: construção e aplicação
}

\author{
Mary Vonni Meürer de Lima \\ Universidade Federal de Santa Catarina \\ mary.meurer@ufsc.br \\ Berenice Santos Gonçalves \\ Universidade Federal de Santa Catarina \\ berenice@cce.ufsc.br
}

Resumo: O processo de seleção de fontes tipográficas para um projeto consiste em uma etapa fundamental e complexa, principalmente para graduandos em Design. Buscando uma ferramenta para sistematizar e orientar este processo foi construída uma Matriz de Seleção Tipográfica baseada em cinco critérios e com variações de peso para cada um de acordo com as características do projeto. Esta matriz foi aplicada a dois grupos de alunos do curso de Design da UFSC, nas disciplinas de Projeto Editorial e Projeto Web. Posteriormente, a partir de um método prospectivo, estes alunos responderam um questionário sobre o uso da matriz que resultou em uma avaliação positiva da ferramenta pela maioria dos participantes.

Palavras-chave: tipografia, critérios de seleção, matriz de seleção.

\begin{abstract}
The process of selection of typographic fonts for a project consisting of a fundamental and complex stage, mainly for undergraduate Design. Seeking a tool to organize and guide this process was built a Matrix of Selection Typographic based on five criteria and weight variations for each one according to the characteristics of the project. This matrix was applied to two groups of students of Design UFSC, in the disciplines of Editorial Design and Web Design. Subsequently, from a prospective method, these students answered a questionnaire on the use of the matrix which resulted in a positive assessment of tool by most participants.
\end{abstract}

Keywords: typography, selection criteria, selection matrix. 


\section{INTRODUÇÃO}

O campo de atuação do designer gráfico é amplo. Este desenvolve projetos editoriais, de identidade visual, interfaces, embalagens, sinalização, ilustração, entre outros. Em praticamente todas estas áreas projetuais a tipografia está presente. A própria criação de fontes também consiste numa atividade desenvolvida pelo designer.

Para melhor compreensão do termo e sua abrangência recorre-se a Farias (2013 p. 18) que define Tipografia como

O conjunto de práticas subjacentes à criação e utilização de símbolos visíveis relacionados aos caracteres ortográficos (letras) e para-ortográficos (tais como números e sinais de pontuação) para fins de reprodução, independentemente do modo como foram criados (a mão livre, por meios mecânicos) ou reproduzidos (impressos em papel, gravados em documento digital).

As práticas relacionadas à utilização dos símbolos tipográficos corresponde a macrotipografia, que segundo Kunz (2004) envolve a composição das palavras e da página, abordando alinhamentos, colunas de texto, entre outros elementos. Dentre as questões envolvidas na composição da página e consequentemente do projeto gráfico como um todo, este artigo dará destaque para uma das etapas iniciais que consiste na escolha das fontes tipográficas.

Uma combinação de fontes mal elaborada pode gerar um projeto gráfico, tanto impresso quanto digital, inconsistente, com problemas de legibilidade e inadequado ao público e a mensagem. A seleção destas fontes não pode, portanto, ser aleatória, sem critérios ou apenas baseada nas preferências do designer.

Saber escolher as fontes adequadas para um projeto torna-se mais difícil à medida que mais opções estão disponíveis, porém sem garantia de qualidade. Mesmo quando existe a qualidade é preciso critério para reconhecer qual a fonte ideal diante de tantas possibilidades. Conforme observa Bringhurst (2005)

\footnotetext{
Alguns dos melhores tipógrafos que já existiram possuíam apenas uma fonte romana por vez, uma gótica e uma grega. Outros podiam ter até cinco ou seis romanas, duas ou três itálicas, três góticas e três ou quatro gregas. Hoje, o tipógrafo pode comprar fontes aos milhares em CDs e copiar muitos outros milhares da internet: mais fontes do que qualquer ser humano poderia usar, e ainda assim uma seleção sempre incompleta.
}

Se a seleção de fontes pode ser considerada complexa em situações de projeto, com certeza este processo é ainda mais complexo para estudantes que estão adquirindo repertório na área da tipografia.

Assim, com o objetivo de oferecer aos acadêmicos de design uma alternativa para orientar o processo de seleção de fontes foi desenvolvida uma Matriz de Seleção Tipográfica. Portanto, no presente artigo, apresenta-se o processo de construção e aplicação desta matriz, bem como os resultados de um questionário aplicado a duas turmas de graduação para identificar suas percepções sobre o uso da mesma. 


\section{FUNDAMENTOS PARA CONCEPÇÃO DA MATRIZ}

A etapa inicial da pesquisa consistiu na realização de uma revisão bibliográfica para identificar os critérios e recomendações apresentados por diversos autores da área , tais como Frutiger (2001), Bringhurst (2005), Jury (2006), Gruszynski (2008), Fontoura e Fukushima (2012), Farias (2013) e Lupton (2013) sobre parâmetros e critérios envolvidos na escolha de fontes para um projeto tipográfico. Após a análise destas informações foram definidos 5 critérios, a saber: Legibilidade, Expressão, Família, Qualidade e Direito de Uso a seguir apresentado. Cabe ressaltar que a relevância de cada critério varia de acordo com a natureza do projeto, o público, a aplicação da fonte, enfim, as particularidades de cada briefing.

\subsection{Critérios de Seleção}

De acordo com Bringhurst (2005 p. 24 e 29) "palavras bem escolhidas merecem letras bem escolhidas" caso contrário "aquilo que as palavras dizem linguisticamente e aquilo que as letras inferem visualmente ficam dissonantes, desonestos e desafinados".

Em relação aos critérios para uma escolha adequada de fontes tipográficas Bringhurst (2005) apresenta 12 recomendações que foram consideradas como base para este artigo.

- Escolha fontes apropriadas à tarefa e ao assunto.

O autor considera relevante que uma fonte apresente ornamentos e fantasias que remetam à temática do projeto, porém destaca que a qualidade e a legibilidade, nesta ordem, são mais importantes.

- Escolha fontes que possam fornecer todos os efeitos de que você precisar.

Ao escolher uma fonte é preciso verificar se ela contém todos os caracteres, pesos e variações que serão necessários.

- Tire o máximo proveito daquilo que utilizar.

Se existe uma restrição quanto às fontes que poderão ser usadas em um projeto, o designer deve procurar enfatizar as qualidades destas fontes e usa-las da melhor forma possível.

- Escolha uma fonte na qual os ecos e as associações históricas estejam em harmonia com o texto.

Se o texto trata de determinada época e existe uma fonte tipográfica equivalente, que reforça as características desta época ela deverá ser usada.

- Deixe que o tipo fale seu idioma natural.

Ainda sobre a questão histórica o autor observa que ao usar, por exemplo, uma fonte Renascentista, o designer deve buscar referências sobre a composição, as margens, a indicação de citações, enfim, aprender o idioma tipográfico da época.

Escolha fontes cujo espírito e caráter individual estejam de acordo com o texto. 
Fontes escolhidas de acordo com as suas origens, suas formas, e até mesmo características dos tipógrafos que as criaram tendem a gerar resultados mais interessantes.

- Comece com uma única família tipográfica.

Segundo o autor a maioria das páginas e muitos documentos podem ser compostos com apenas uma família tipográfica, desde que essa seja suficientemente completa.

- Respeite a integridade do romano, do itálico e do versalete.

Estes tipos constituem a tríade básica de uma família, mas é sempre importante analisar cada um separadamente, além do próprio conjunto.

- Avalie os tipos bold por seus próprios méritos.

O autor observa que os tipos romanos bold foram inventados no século 19 , portanto muitas versões bold de fontes anteriores a este período são adaptações da tipografia digital que não mantém as características originais.

- Escolha fontes titulares e display que reforcem a estrutura da fonte de texto.

Ao definir a combinação de fontes é importante considerar as características individuais e buscar fontes que se complementem. Por exemplo, uma fonte geométrica de auto contraste como a Bodoni não é adequada para ser usada nos títulos de um texto escrito em Garamond, cujo contraste é mínimo e o desenho remete a uma estrutura caligráfica.

- Combine fontes serifadas e sem serifa com base em uma estrutura interna.

Quando não for usar fontes da mesma família é preciso ter mais critério para escolher serifadas e não serifadas. Como no caso anterior é preciso observar a estrutura da fonte ou buscar soluções do mesmo tipógrafo.

\section{- Verifique a licença antes de afinar uma fonte digital}

Sobre a licença de uso da fonte é importante destacar que algumas empresas desenvolvedoras - type foundries, permitem que a fonte seja editada para atender as necessidades do usuário, porém alertam que a fonte não pode ser vendida ou distribuída com estas correções. Mas em alguns casos a licença informa que nenhum tipo de edição é permitido, mesmo para uso pessoal. (BRINGHURST, 2005)

Relacionando estas recomendações é possível perceber referências à qualidade da fonte, aos seus aspectos históricos e expressivos, ao uso de famílias tipográficas e a questões relacionadas à licença de uso.

A partir destas informações buscou-se suporte em outros autores como Frutiger (2001), Jury (2006), Gruszynski (2008), Fontoura e Fukushima (2012), Farias (2013) e Lupton (2013). Comparando as recomendações e critérios apresentados por eles constatou-se que a Legibilidade é a questão mais abordada por todos os autores pesquisados. 
Referências a Expressão da fonte como elemento de comunicação também foram encontradas em todos os autores, porém, com menos ênfase do que a Legibilidade.

Sobre Família Tipográfica foram encontradas informações principalmente em Frutiger (2001) e Bringhurst (2005), mas também alguns conceitos em Gruszynski (2008) e Lupton (2013). Questões referentes à qualidade são abordadas em Frutiger (2001) e Bringhurst (2005) e Jury (2006).

Sobre Direito de Uso não foram encontradas informações para complementar as considerações de Bringhurst (2005), mas mesmo assim o critério foi mantido pois é fundamental que o aluno compreenda e respeite as licenças de uso.

Desta revisão bibliográfica foram extraídos os conceitos e recomendações apresentados a seguir.

\subsubsection{Legibilidade}

Segundo Fontoura e Fukushima (2012), Jury (2006), Tracy (apud FARIAS, 2013) a legibilidade está relacionada com o design de tipos, com a clareza dos caracteres e a velocidade com que podem ser reconhecidos. É claro que existe uma relação com o uso da fonte, ou seja, onde será aplicada, a diagramação da página, a organização do texto, que implica em sua leiturabilidade.

Ao escolher uma fonte priorizando a sua legibilidade é importante definir o que vai ser lido, ou seja, a quantidade de texto, qual a sua função, se é informativo, instrutivo ou para entretenimento, quem vai ler e em quais circunstâncias e ambiente. (FONTOURA E FUKUSHIMA, 2012)

Além da anatomia dos caracteres, presença ou não de serifa, espaço interno, altura de $x$ e espessura do traço outro fator pode influenciar na legibilidade de uma fonte, a familiaridade do leitor com a mesma. Segundo Farias (2013 p. 106) em depoimento à revista U\&lc a tipógrafa americana Zuzana Licko argumenta que:

Legibilidade é neutralidade. As fontes mais populares são as mais fáceis de ler; a popularidade fez com que elas desaparecessem de nossa cognição consciente. Depois de um certo tempo, é impossível dizer se elas são fáceis de ler porque são muito usadas, ou se são muito usadas porque são fáceis de ler.

\subsubsection{Expressão}

A expressão, ou seja, o que o desenho dos caracteres representa em termos de história, cultura e estilo é fundamental para a comunicação.

Ao escolher as fontes, os designers gráficos consideram a história dos tipos e suas conotações atuais, bem como suas qualidades formais. O objetivo é encontrar uma combinação apropriada entre o estilo das letras, a situação social específica e a massa de conteúdo que definem o projeto. Nenhuma cartilha é capaz de fixar o significado ou a função de cada fonte, cada designer deve enfronhar-se nessa biblioteca de possibilidades à luz das circunstâncias únicas de cada projeto. (LUPTON, 2013 p. 28) 
De acordo com Gabriel Martinez Meave, citado por Fontoura e Fukushima (2012 p. 63), além de ser legível e funcional a tipografia também precisa expressar a cultura, os desejos e os pensamentos de quem escreve. Deve, portanto diferenciar não só pelo conteúdo, mas também pela forma, um texto técnico, uma poesia ou uma carta de amor.

Os leitores são capazes de compreender os diversos estilos existentes hoje, com maior ou menor esforço e dependendo do seu interesse pelo texto (FRUTIGER, 2001). Cabe ao designer saber equilibrar o uso de fontes mais ou menos expressivas, buscando tornar o projeto interessante para despertar a atenção do leitor $\mathrm{e}$ oportunizar uma leitura agradável.

\subsubsection{Família}

Uma família tipográfica corresponde a um conjunto de fontes com características semelhantes, porém com variações de peso, espessura e inclinação. Por exemplo, a família Arial que é composta pelas fontes Arial Black, Arial Narrow, Arial Rounded, entre outras. (GRUSZYNSKI, 2008 p. 29)

De acordo com Bringhurst (2005) as fontes da mesma família apresentam variedade e homogeneidade, mantendo uma mesma cultura tipográfica. Este recurso pode ser adequado para alguns projetos, mas para outros pode ser necessário acrescentar fontes que não pertençam a família, com o objetivo de enriquecer a composição.

Segundo Lupton (2013) uma família de tipos romanos, ou seja, serifados, costuma ter poucas variações, geralmente uma romana e uma itálica com pesos bold e semibold. Já as famílias sem serifa possuem mais variações, como versões fino, leve, preto, ultraestreito, estreito, entre outras. Um exemplo é a família Univers criada por Adrian Frutiger em 1957 com 21 versões em 5 pesos e larguras, todos projetados simultaneamente, como um sistema.

Dependendo da complexidade do projeto pode ser necessária uma família mais ou menos completa. Frutiger (2001) sugere que para livros uma família composta por três variações, normal, itálico e semibold, já é satisfatória.

Dehon e Rocha (2006) concluem que

Importa deste modo, para projetos de maior complexidade e/ou abrangência - como projetos gráficos editoriais e/ou alfabetos institucionais - considerar a existência de variações de peso, largura e inclinação. Deste modo a seleção se dá a partir de um estilo, chegando a uma família tipográfica e, nesta, observando sua completude a partir das variações descritas. No caso de a família não apresentar o número de variações necessárias, parte-se para a escolha de outra família tipográfica de mesmo estilo.

\subsubsection{Qualidade}

O surgimento do desktop publishing a partir da década de 1980 contribuiu muito para a popularização do design de tipos. O que antes era desenvolvido apenas por experientes tipógrafos que planejavam por anos a criação de uma família 
tipográfica passou a ser possível para qualquer pessoa que tivesse acesso aos softwares e conhecimentos mínimos sobre tipografia.

Além de facilitar o processo de criação das fontes o computador trouxe a possibilidade de distribuir, de forma gratuita ou comercialmente, essas fontes sem que exista nenhum critério de avaliação. Portanto acabe ao designer avaliar se a fonte escolhida possui qualidade suficiente para atender as demandas do projeto.

Para verificar a qualidade é recomendável aplicar a fonte em um texto e observar se o kerning, espaço entre pares de letras, é adequado, se a fonte possui todos os caracteres e sinais essenciais, se as curvas estão bem desenhadas e se a fonte se adapta as variações de tamanho. (ROCHA, 2002)

\subsubsection{Direito de Uso}

O direito de uso de uma fonte ou família tipográfica possui basicamente cinco categorias: livre, livre para uso pessoal, fontes do sistema operacional, fontes pagas e proprietárias, neste caso, feita exclusivamente para uma empresa.

Quando a fonte é paga o comprador deve adquirir uma licença para cada máquina, podendo fazer uso livre em seus projetos. Porém não tem o direito de enviar o arquivo da fonte para terceiros, por exemplo, o cliente ou a gráfica que irá imprimir o material.

O uso de fontes pagas em projetos web constituía um problema a parte, uma vez que o usuário precisaria ter a mesma fonte instalada em seu computador para visualizar o site. Para solucionar este problema foi desenvolvido o Web Open Font Format (WOFF), um protocolo aberto de fonte, desenvolvido pelos de designers Tal Leming e Erik van Blokland e por Jonathan Kew da Mozilla que possibilita o uso de fontes diferenciadas nos projetos web, com um download rápido e garantindo os direitos autorais. (W3C, 2012)

Ao selecionar as fontes para um projeto é importante que o designer defina se haverá verba para a compra de fontes ou se deve usar apenas fontes de sistema ou outras fontes gratuitas.

\section{PROCEDIMENTOS METODOLÓGICOS: A CONSTRUÇÃO E APLICAÇÃO DA MATRIZ}

Estabelecidos os critérios básicos para a seleção de fontes para um projeto gráfico buscou-se uma forma de sistematizar este processo. Foi construída a matriz de avaliação a partir da estrutura proposta por Baxter (2000 p. 64) para seleção de alternativas de projeto.

As alternativas são colocadas nas colunas e os critérios de seleção nas linhas da matriz. As células da matriz são preenchidas, fazendo-se a avaliação de cada alternativa em relação aos diferentes critérios (no sentido horizontal) ou, alternativamente, quais são as melhores e piores alternativas em relação aos critérios (no sentido vertical). É uma técnica importante no planejamento do produto, projeto conceitual e configuração do projeto. 
O autor sugere ainda que os critérios tenham pesos diferentes de acordo com a sua relevância em cada projeto, variando de 1 a 5, ou 1 a 10, por exemplo. Esta possibilidade é fundamental no caso da seleção de fontes tipográficas pois, conforme apresentado anteriormente, a importância da legibilidade, assim como dos outros critérios, pode variar de um projeto para o outro. É válido destacar que a atribuição dos pesos deve estar de acordo com o briefing e os objetivos pré-definidos, não podendo ser aleatória.

No caso de projetos maiores, em que há necessidade de selecionar fontes para aplicações diferentes, para o título e para o texto, é recomendável fazer uma matriz para cada aplicação. Esta separação justifica-se pelo fato de que os pesos podem variar, por exemplo, para escolher a fonte do título é provável que o critério expressão seja mais relevante que a legibilidade.

Para cada fonte analisada deve ser atribuída uma nota, sugere-se a escala de 0 a 5 , e depois é feita a somatória. As fontes com maior pontuação devem ser consideradas as mais adequadas ao projeto, como mostra a tabela 1.

Tabela 1 - Exemplo da Matriz de Avaliação Tipográfica

\begin{tabular}{lllllll}
\hline Fonte & \multicolumn{2}{l}{$\begin{array}{l}\text { Legibilidadep ExpressãopeFamíliapeso Qualidadep } \\
\text { eso } 5\end{array}$} & so 3 & 5 & Direito de & Total \\
& & 4 & 1 & 3 & 5 & \\
\hline Fonte 1 & 2 & 3 & 5 & 5 & 2 & 47 \\
\hline Fonte 2 & 5 & 5 & 2 & 2 & 3 & 46 \\
\hline Fonte 3 & 1 & & & & & \\
\hline
\end{tabular}

Fonte: Elaborado pelas autoras, com base na pesquisa realizada.

\subsection{Aplicação}

A matriz foi apresentada aos alunos do curso de Design da Universidade Federal de Santa Catarina, nas disciplinas de Projeto Editorial (projeto 5) e Projeto Web (projeto 6) no segundo semestre de 2013. No caso da disciplina de Projeto Editorial o mesmo grupo de alunos estava cursando também a disciplina de Tipografia. Já na turma de Projeto Web a maioria dos alunos já havia passado por esta disciplina.

Ao iniciar a etapa criativa dos projetos os alunos foram orientados a usar a matriz para selecionar as fontes necessárias para compor os textos. Após uma breve explicação sobre como montar e aplicar a matriz, cada dupla de projeto teve autonomia para definir quantas matrizes seriam feitas e quantas fontes fariam parte da seleção. A aplicação da matriz foi realizada pelas equipes individualmente e extraclasse, ou seja, não houve acompanhamento durante o processo.

$\mathrm{Na}$ semana seguinte os alunos entregaram as matrizes e foram convidados, a responder um pequeno questionário com perguntas abertas e fechadas, onde indicaram as possíveis dificuldades no uso. 


\section{RESULTADOS E DISCUSSÃO}

O questionário apresentado aos 23 alunos, sendo 7 de Projeto Web (PW) e 16 de Projeto Editorial (PE), continha oito questões que abordavam os seguintes assuntos:

- facilidade de compreensão da matriz;

- a relevância dos critérios;

- o número de matrizes feitas e fontes analisadas;

- a dificuldade ou não em estabelecer os pesos;

- a produtividade do processo de aplicação da matriz;

- a satisfação ou não com o resultado obtido;

- a opinião sobre todo o processo e o resultado.

Sobre o primeiro item, a facilidade de compreensão da matriz, 4 dos 7 alunos de PW declararam ter compreendido facilmente como aplicar a matriz, mesmo sem a explicação. Já em PE 9, dos 16, consideram a aplicação fácil, mas após receber a explicação. E um aluno registrou que foi preciso pedir uma nova explicação para conseguir aplicar a matriz.

Em relação aos critérios pré-definidos para a matriz, 20 dos 23 alunos de PW e PE consideram todos os critérios relevantes. Apenas 1 aluno de PE sugeriu que o critério Expressão fosse retirado e 1 aluno de PW sentiu a necessidade de mais critérios, sugerindo que a Qualidade fosse subdividida.

Sobre o número de matrizes aplicadas tanto em PW quanto em $\mathrm{PE}$ um número equivalente de alunos, 11 e 11 optou por fazer 1 ou 2 matrizes. Apenas 1 aluno de PE declarou ter feito 5 matrizes.

Quanto ao número de fontes analisadas em cada matriz, que os alunos também tinham autonomia para definir, houve uma variedade mais acentuada. Dos 23 alunos 6 usaram a matriz para escolher entre 2 fontes, 5 alunos analisaram 3 fontes, 4 analisaram 4 fontes por matriz, 3 alunos analisaram 5, 1 aluno analisou 7 e 2 alunos analisaram mais de 8 , sendo que um destes analisou 13 fontes em uma mesma matriz. No caso específico dos alunos de PE, 2 declararam ter usado a matriz para analisar apenas 1 fonte.

Em relação à atribuição de pesos para cada critério, os alunos de PW 5 não declararam dificuldade nesse processo. No PE 10 de 16 alunos, explicitaram que não tiveram dificuldade em atribuir os pesos.

Sobre o processo de aplicação da matriz, no caso dos alunos de PW, 4 consideram produtivo embora um pouco demorado e 3 consideram rápido. Em PE 9 dos 16 consideraram o processo rápido, para 3 foi produtivo embora demorado e para 4 o processo foi cansativo. 
Quanto ao resultado, ou seja, a fonte indicada como mais apropriada de acordo com os critérios, 21 alunos consideraram satisfatório e 2 alunos marcaram a opção surpreendente, pois numa avaliação superficial esperavam outro resultado.

Na última questão que pedia uma opinião sobre todo o processo e o resultado 17 dos 23 alunos optaram por satisfatório e 6 por muito relevante.

Considerando os resultados apontados é possível afirmar que a matriz é eficiente, porém, necessita de alguns ajustes para melhorar a sua eficácia, ou seja, facilitar o processo de aplicação e torná-lo menos demorado. Um dos pontos a ser discutido é o número de fontes por matriz. É preciso estabelecer um número mínimo e máximo, para que a aplicação não seja incompleta nem demorada demais.

Sobre a definição do peso para cada critério no caso dos alunos de PE houve um número relevante, 9 de 16 , que declarou ter dificuldade para definir. Para esclarecer melhor essa questão e entender quais as dificuldades encontradas será necessária uma nova pesquisa, com caráter qualitativo.

\section{CONCLUSÃO}

O estudo realizado, que evidenciou a construção da matriz, a aplicação e a realização de entrevistas, mostrou-se pertinente para o entendimento da especificidade dos critérios empregados e para investigação de possíveis desdobramentos dos critérios.

Destaca-se, por exemplo, a sugestão de um dos alunos para subdividir o critério "Qualidade" e a de outro aluno que indicou que o critério "Expressão" deveria ser revisto. Em ambos os casos não houve maior detalhamento, pois o questionário não apresentava um campo para tal informação.

Além de realizar o aprimoramento da matriz e propor sua aplicação para outros grupos de alunos, inclusive em outros tipos de projetos, pretende-se ainda realizar um acompanhamento para identificar se as fontes selecionadas apresentaram um resultado satisfatório ao serem efetivamente usadas nos projetos.

Outro desdobramento desta pesquisa será estabelecer critérios também sobre a combinação de fontes em um projeto, ampliando desta forma a relevância da matriz.

\section{REFERÊNCIAS}

BAXTER, Mike. Projeto de Produto. São Paulo: Edgard Blücher, 2000.

BRINGHURST, Robert. Elementos do Estilo Tipográfico. São Paulo: Cosac Naify, 2005.

DEHON, Heric e ROCHA, Cleomar. Processo de seleção tipográfica:

os critérios técnicos. Revista do Seminário Estudantil de Produção Acadêmica UNIFACS. Salvador. V. 10, n.1 , 2006. Disponível em: http://www.revistas.unifacs.br/index.php/sepa/article/view/28/22. Acesso em: 25 de abril de 2014.

FARIAS, Priscila Lena. Tipografia Digital: o impacto das novas tecnologias. 4a ed. Teresópolis: 2AB, 2013. 
FONTOURA, Antônio M. e FUKUSHIMA, Naotake. Vade-mécum de Tipografia. Editora Insight, 2012.

FRUTIGER, Adrian. Sinais \& Símbolos: desenho, projeto e significado. São Paulo: Martins Fontes, 2007

GRUSZYNSKI, Ana Claudia. Design Gráfico: do invisível ao ilegível. São Paulo: Rosari, 2008.

JURY, David. O que é a Tipografia. Portugal: Gustavo Gili, 2006.

KUNZ, Willi. Tipografía Macro y Micro Estética. México: Gustavo Gili, 2004.

LUPTON, Ellen. Pensar com tipos: um guia para designers, escritores, editores e estudantes. São Paulo: Cosac Naify, 2013.

ROCHA, Cláudio. Projeto tipográfico - análise e produção de fontes digitais. São Paulo: Rosari, 2002.

W3C Recommendation. WOFF File Format 1.0. Disponível em: http://www.w3.org/TR/2012/REC-WOFF-20121213. Acesso em: 25 de abril de 2014. 